\title{
Learning Style in Language Learning Classroom
}

\author{
Fitri Devi Enjelina Silitonga, Sri Menty Pinem, Lovita Simbolon, \\ Laura Maloni Lingga, Erikson Saragih \\ English Education Department, Universitas Prima Indonesia \\ English Education Department, Universitas Prima Indonesia \\ English Education Department, Universitas Prima Indonesia \\ English Education Department, Universitas Prima Indonesia \\ English Lecturer, Prima Indonesia University, Indonesia \\ Email: vitauli1997@gmail.com
}

\begin{abstract}
This article describes the concept of language learning styles in the classroom and the characteristics of students for each of their learning styles in language learning. Where the purpose of this study is to describe their learning styles related to learning styles for language acquisition. There are 3 types of language learning styles described by Tekavcic and Dimovski namely the visual, auditory and touch functions of a person in processing information. The three main types of learning styles are not absolute, of course. Many students learn through various senses. Certain students may be as strong in three perceptual modalities, or in two perceptual modalities from any combination. The method of data collection in this study is observation, the results of this discussion are that we observed grade 9 students of Percut Sei Tuan Middle School very less on how to apply language learning styles they are in front of the class so that it impacts learning difficulties well.
\end{abstract}

Keywords: Learning Style; Language Learning.

\section{INTRODUCTION}

The new field of study. learning. According to Nasution Learning styles place more emphasis on students responding to and benefiting from the programs provided, while many teachers choose to use their own learning styles in class. It must be realized that the teacher has their own chosen learning style and the teacher must be responsible for the learning style requested by each learner. In addition, students must participate to develop independence inside and outside the classroom. They must be equipped with facilities to guide themselves, so they can accept the responsibility for

(2011) learning style is the way students support and use the stimuli received in the learning process. According to the author, the learning style is the way students make a strategy in learning and can support the person's results. This study explains the concept of learning styles and characteristics of students from each student's learning style in language learning. In the first part of this article, the author studies learning styles. According to Deporter and Hermacki (2011) Learning style is a combination of how a person 
combines, then organizes and processes information, sees, hears, writes and says. However, aspects of information, analytics, global or leftbrain right brain, another aspect is the compilation of responding to something on the learning environment (absorbed abstractly and concretely). This study explains the concept of learning styles and characteristics of students from each student's learning style in language learning. In the first part of this article, the author studies learning styles. Then the author will be associated with learning styles to obtain language. There are 3 types of language learning styles compiled by Tekavcic and Dimovski namely the visual, auditory and touch functions of a person in the information process. The three main types of learning styles aren't course. Many students learn through various senses. Certain students may be as strong in three perceptual modalities, or in two perception modalities from any combination.

\section{RESEARCH METHOD}

\subsection{Learning Styles: An Overview}

Proficiency in a second language could not merely be described in terms of structures, phonology, morphology, and lexicon of the target language. This kind of knowledge is not adequate for learners who learn a second language for the utility function. In foreign language classrooms or in second language acquisition, we should acknowledge that learners differ in a wide variety of ways. These differences are usually called individual differences. The students' individual differences in the second language classroom can be age, aptitude, motivation, attitude, learning style, and personality style. One of the individual differences: learning style will be the main concern of this study.

\subsection{Concept of Learning Style}

Learning Style as consisting of distinctive behavior which serves as indicators of how a person learns from an adapt to this environment. It also gives clues to how a person's mind operates (Gregore, 1979: 324). Dunn (1984: 45) stated that learning style represents each person biologically and experientially Inducing characteristics that either foster or inhibit achievement.

On the surface, the concepts of learning style appear to be contradictory. The notion of learning style implies individual differences. As pointed out, learning style is pervasive quality in the learning strategies or the learning behavior of an individual (Reid, 1987:89). A basic assumption underlying the devolvement of learning style instruments is the existence of an individual is different. Learning style instruments are designed to distinguish one kind of learner from another. If all students learned in the same manner, learning style inventories would be unnecessary. Language teachers should understand what learning style is. Learning style is one of the factors that may affect the learning process in second language acquisition. 
Different experts have a different concepts of learning style. The following are some different definitions of learning styles.

a. The learning style describes a student in terms of those educational conditions under which he/she is most likely to learn. Learning Style describes how a student learns, not what he has learned. Hunt then narrows his definition by dealing with how much structure needs in order to learn best (Hunt, 1979:27).

b. Learning style has been defined as "cognitive, affective, and traits that are relatively stable indicators of how learners perceive, interact with and respond to the learning environment (Keefe,1979:4).

c. Learning style is defined as preferred or habitual patterns of mental functioning and dealing with new information (Ehrman, 1990:311).

All of the definitions above actually share a similar concept, but they are expressed in different ways that are the way in which each person has preferences for the ways they like to absorb and retains new information which can change his/her behavior.

\subsection{Theories of learning}

The starting point of all language teaching should be understood of how people learn(theories of learning). Identifies the devolvement in learning theory into five main stages; behaviorism, mental, cognitive code, affective factor, and learning and acquisition (Hutchinson,1987:39).

\section{a. Behaviorism}

The theory points out that learning is a mechanical process of habit sequence. This method laid down a set of guiding methodological principles, based on the behaviorist stimulus-response and secondly assumption that second formation and proceeds by means of the frequent reinforcement of stimulusresponse learning should reflect and imitate the perceived process of mother tongue learning. It also implies that a teacher should expose learning activities and language inputs which can stimulate interest, react and communicate they are learning.

\section{b. Mentalism}

Chomsky concluded that thinking must be ruled-governed; a finite, and fairly small, set of rules enables the mind the deal with the potentially infinite range of experiences it may encounter (Hutchinson, 1987:42). This can also be hypothesized that when a learner has a good commanding structure, he/she will easily master the target language he/she learning.

\section{c. Cognitive code}

This theory views learners as thinking beings. Learning as a process in which the learners actively try to make sense of data, and data can be said to have taken place when the learners have managed to impose a 
sort of meaningful interpretation or patterns on the data. The basic teaching-technique as associated with a cognitive theory of language learning is the problem- solving task.

\section{$\mathrm{d}$. The affective factors}

This stage views learners as emotional beings. People do not only think, but also have feelings. Learning, particularly the learning of a language is an emotional experience, and the feeling that the learning process evokes will have a crucial bearing on the success or failure of the learning. The importance of emotional factors is easily seen if we consider the relationship between the cognitive and affective aspects of learning one of vitally important elements in foreign language settings, especially in the development of ESP (English for Specific Purposes).

e. Learning and acquisition

Krashen in Hutchinson (1987:49) made a distinction between learning and acquisition. Learning is seen as a conscious process, while acquisition proceeds unconsciously. For second language learning, both processes are likely to play in a useful part.

\subsection{Research Findings and Discussion}

\subsubsection{Types of Learning Style}

Barsch in Davis (1989:6) stated that approaches learning style from the point of view for perceptual modality preferences. There are three main types of learning style

\section{Visual learners}

Learn more effectively through the eyes (seeing). A visual learner usually works best alone or perhaps with one another person, for reading and reviewing, visual learners well from seeing words in books. They remember and understand information and instruction better if the teachers read them. Visual learners do not need much oral explanation as auditory if they want to remember information. The visual learners oftentimes prefer to be left alone in his own space to read or to study quietly as far away as possible from a verbal learner who needs to discuss everything. They should take every opportunity to write down or to draw the incoming auditory information. They will also translate the given information into either words or pictures.

\section{Auditory learners}

Learn more effectively through the ear (hearing). Auditory learners may benefit from soft background music. Auditory learners learn from hearing words spoken and from oral explanation. They may remember information by reading a loud or moving their lips as they read especially when they are learning new material. Auditory learners learn to benefit from hearing audiotapes lectures and class discussions. The auditory learner is one who can learn best by hearing, listening, or speaking. This type of learner does not necessarily make pictures in his mind but will clarify the given information through his listening and repeating 
skills. It comprises the listening learner and the auditory learner.

\section{Tactile learner}

Learn more effectively through the sense of touch (hands-on). Tactile learners learn best when they have the opportunity to do "hands-on" experiences with materials. That is, working on experiments in a laboratory, handling, and building models, and touching and working with materials provide them with the most successful learning situation. Writing notes or instructions can help them remember information, and physical involvement in class-related activities may help them understand new information. The tactile learner usually needs more concrete experiences to learn what is being taught. In a classroom setting, they may learn best if the assignments are geared to hands-on activities (experiments, concrete materials, trial errors, and trips).

The three main types of learning styles are not absolute, of course. Many learners learn through a variety of senses. Certain students might equally be strong in the three perceptual modalities, or in two perceptual modalities of either combination.

\subsubsection{How to Identify Learning Style}

Learning Style Inventory which is simple test helps the students understand the strength and the weakness as learners. He approaches learning style from the point of view perceptual modality preferences. It consists of 30 questions based on leading to perceptual modalities (Davis, 1989:6). In this research, the writer used Learning Style Inventory, the choice is based on that the learning styles based on the perceptual modality preference can sufficiently reveal the prominent characteristics of individual learners in learning, and more importantly that those learning styles have a clear practical relationship with the media, kind of materials, how the implementation

Identification is done to knowing the learning style or we can say for grouping purposes. Many teachers ignore the possibility the students are not learning because they are not the opportunity to use their own style of learning classroom.

\subsubsection{Concept Language Acquisition}

Before discussing the second language acquisition, it is necessary to have a clear notion of language acquisition. It seems that they do not have an opinion about it. They view language acquisition from different points of views as reveal in the following:

a. Richard (1985:3) reveals that language acquisition is the process by which a person learns a language. It is called acquisition because some linguist believes that the development of the first language in a child is a special process.

b. David (1991:5) reveals that language acquisition refers to the process or result of learning a particular aspect of language, 
and finally the language as a whole. The acquisition is also used in the context of learning a foreign language. Foreign or second language acquisition is thus distinguished from first language or mother tongue acquisition. In this context, the acquisition is sometimes opposed to "learning". The former is viewed as a subconscious, natural process, which is the primary force behind foreign language fluency. The latter is seen as a conscious process that monitors the progress of acquisition and guides the performance of the speaker.

c. Krashen

distinguished between acquisition and learning language. Acquisition acquired first and second languages. It is a subconscious process; language communication and usually aware of the fact that they are using language communication and their acquired competence is also subconscious. In addition, the acquisition includes implicit learning, informal learning, and natural learning. Whereas "learning" includes formal knowledge of a language, explicit learning. He further states that language acquisition is also available to the adults' second language performer. d. Bahri (1997:14) reveals that acquisition although sometimes is distinguished from learning, is used in the present study follow must researchers in the field who use it, as the superordinate term both acquisition and learning. He further states that we do retain the term learners to refer to those in the process of acquiring a second language.

Based on the opinion of the experts above, the writer can conclude that language acquisition is the process of acquiring the first language and the second or foreign language.

\subsubsection{Concepts of Second Language Acquisition}

Second language acquisition is a process of enormous complexity in which a variety of factors are at work and which evades description, let alone explanation (Klein, 1986:23).

The systematic study of how people acquire the second language is a fairly phenomenon belonging to the second half of the twentieth. At first sight, the meaning of the term 'second language acquisition' seems transparent but, in fact, it requires careful explanation. For one thing, in this context 'second' can refer to any language that is learned subsequent to the mother tongue. Also 'second' is not intended to contrast with 'foreign'. Whether you are learning a language naturally as a result of living in a country where it spoken or learning it in a classroom through instruction, it is customary to speak 
generally of 'second' language acquisition.

Second language acquisition then can be defined as the way in which people learn a language other than their mother tongue, inside or outside of the classroom, and SLA (Second Language Acquisition) as the study of this.

\subsubsection{Learning Style in Second Language Acquisition}

The physical elements of learning style all need to be considered when one teacher. The learning style in second language acquisition might prefer auditory, visual and tactile or combination learning. The students' ESL (English as a Second Language) seems to be on the right track in addressing students' perceptual learning styles.

Knowledge of one's own learning style is fundamental in "learning to learn." Students can be expected to acquire successfully language acquisition strategies study methods, or collaborative learning skill.

\subsubsection{Assumptions on Perceptual Learning Style}

Perceptual learning style described by Tekavcic and Dimovski as the domination of visual, auditory and tactile functions of someone in processing information. The following are the characteristics of each type of learner (Dunn, 2003:1).

A visual learner is characterized by mind sometimes strays during verbal activities, observes, rather than talks or acts; maybe quite by nature, organized in the approach to tasks, like to read, usually a good speller, memorize by creating mental images, thinks in pictures, easily put off by visual distraction, finds verbal instructions difficult remembers faces strong on first impressions, likes drawing and doodling, may have good handwriting, enjoys using color, notices details, often a quick thinker, and may focus on the 'big picture' and use advanced planning.

An auditory learner generally talks to self-aloud, outgoing by nature, whispers to self while reading, may hum or sing while working, like to be read to, memorizes by steps in a sequence, very aware of rhythm, easily distracted by noises, may have difficulty with written materials, remembers names, may assess people by the sound of their voice, enjoys music and the sounds of words, enjoys talking and listening, and may need time to think (discuss with himself/herself).

A tactile learner generally in the nation most of the time/fidgety, outgoing by nature, expresses emotion by physical means, will try new things-likes to get involved, reading is not a priority, may find spelling difficult, like to solve the problem by physically working through them, enjoy Opportunites to work collaboratively with a partner or a small group on a task, remember what they have don't rather than seen/heard, enjoys handling objects, enjoys doing activities and may need time to think (e.g. process the action involved). 
After having identified the characteristics of the three modalities of perceptual learning preference, it can be found that auditory, visual, and tactile are contrasted in several ways. These three types of learning styles are the main concern of this study. Visual style refers to a preference for learning through vision. Visual learners rely on their sight to take in information and they will lose focus during oral lectures. In contrast, the auditory style refers to the use of hearing sense in getting information. Auditory learners can often follow verbal instructions very well and retain new information better when they talk it out. Those contrastive differences usually bring about serious problems for language teachers in presenting the material. The materials for visual learners may not be suitable for auditory learners and vice versa. An acceptance of learning style differences demands an approach that develops skills through strengths. Once lecturers become aware that different students learn differently, they will be able to accommodate approaches by considering students' different learning styles (Guild, 2001).

In foreign language classrooms, learning style is one of the determinant factors for the success of English learners. Matching students' learning style preferences to specific learning activities can improve learning out came. The student tends to apply and transform the information received into a "style" that matches their strength, based on their experiences and ability.
Every learner will have different ways of developing or organizing her or his ideas in a piece of writing task. Some learners may prefer to use the deductive thinking style while others may prefer to use the inductive ones. Some will prefer to use contrasting in adding details into their paragraphs. Maybe some learners will choose to put their topic sentence at the beginning of the paragraph while others will choose to put it at the end of the paragraph.

Perhaps some learners prefer to describe their ideas of what they have seen while others from what they have heard. The tendency may vary according to the way they perceive information and process it in their minds. The way to communicate the ideas given in the paragraph development will also vary according to their communication styles and ability.

Felder (2004:103) claimed that learning style is not affected by educational background, however, there might be some barriers protecting them against producing a good quality of writing based on their perceptual learning style, such as IQ, prior knowledge of writing skills, knowledge of the target language especially vocabulary and structure element, and socio-psychological and physiological factors.

\subsubsection{Learning Styles and Memory}

Learning styles have closely related to memory. Davis (1989:56) claimed that learning styles such as visual, auditory and tactile come in sensory memory. The sensory 
memory is the place where the information enters the brain through individuals' senses. If the learning styles suitable for individuals' strengths, there will become attention, and then the information can be processed to short-term memory.

Past studies on learning styles and memory found that linking memory and learning styles together depends upon several factors. These factors are background knowledge, interest level, physical state, and emotional state. It is important to know where the learner in regard to these factors to achieve the ultimate learning experience. Kratzig and Arbuthott suggest that helping individuals learn effective memory strategies across all stimulus modalities and context would be beneficial in the learning process (Kratzig, 2003:16).

In general, the result of identifying learning styles demonstrated that an individual's style preference influences the types of learning strategies that she or he employs in acquiring a foreign language. By knowing the learning styles of the learners, the teacher will make groups according to the learners learning styles or we can say for grouping purposes (Harmer, 1991:34).

In Learning Foreign Language students expressed in different ways that are the way in which each person has preferences for the ways they like to absorb and retains new information, which can change his/her behavior. Learning style has the elements of individual qualities, activities, and behavior that are maintained over a long period of time or an individual's natural, habitual and preferred ways and skill, regardless of teaching methods and content area.

Models of learning style can be classified into a dimensional model of perceptual, cognitive, and effective. Perceptual learning style is the physical and sensory elements that a learner uses to interpret external stimuli which are commonly known as visual, auditory, and tactile cultural and gender differences. Besides that in teaching ESL (English as a Second Language) vocabulary also an important thing to know for the learners because vocabulary, as stated in the definition, is a stock of word language. Whatever the style of learning of students may have, they are considered to be an important element in language teaching. Knowing students' learning styles enables teachers to design approaches and methods in teaching a language.

\section{CONCLUSION}

The result of identifying learning styles demonstrated that an individual's style preference influences the types of learning strategies that she or he employs in acquiring a foreign language. By knowing the learning styles of the learners, the teacher will make groups according to the learners learning styles or we can say for grouping purposes (Harmer, 1991:34).

In Learning Foreign Language students expressed in different ways that are the way in which each person has preferences for the ways they like 
to absorb and retains new information, which can change his/her behavior. Learning style has the elements of individual qualities, activities, and behavior that are maintained over a long period of time or an individual's natural, habitual and preferred ways and skill, regardless of teaching methods and content area.

There are 3 types of language learning style described by Tekavcic and Dimovski namely visual, auditory and tactile function of someone in processing information. The three main types of learning styles are not absolute, of course. Many learners learn through a variety of senses. Certain students might equally be strong in the three perceptual modalities, or in two perceptual modalities of either combination. Whatever the style of learning of students may have, they are considered to be an important element in language teaching. Knowing students' learning styles enables teachers to design approaches and methods in teaching a language.

\section{REFERENCES}

Bahri, M. Arifin. 1997. Learning Strategy in Second language Acquisition by Indonesian Adult Learners of English. Cambridge: Basic Blackwell.

David, C. 1991. A Dictionary of Linguistics and Phonetics.

Davis, E.C. 1989. An Integrated Skill Approach, Ujung Pandang, Hasanuddin. Outline of Research for Dissertation. Ujung
Pandang. Hasanuddin University. Candling, Cook. 1991.

Rita Dunn and Shirley A Griggs (Eds). Synthesis of the Dunn and Dunn Learning Style Model Research Who, what, when, where, and so what?. Chapter 1.,PP 1-6 NY: St John's University's Centre for the Study of Learning and Teaching Styles. The Dunn and Dunn Learning Style Model and Its Theoretical Towards Task Based Language Learning. Englewood Cliffs New Jersey . Prentice Hall. 